\section{How to run more equal meetings}

\section{Silje Graffer, Nathalie Rochefort \& Judy Robertson}

In an executive or a scientific meeting, women are not only often under-represented but also not listened to, or their opinions not taken into account. Even worse, whether it is in academia or in the private sector, women often report that they said something at a meeting that was at first not noticed but later on, a male colleague suggested the same idea, sometimes word for word, and suddenly everybody listened and found it very relevant.

This situation is most of the time due to unconscious bias in attention and the way meetings are usually lead. The chair of the meeting is often not conscious of this bias and when a woman points out that her voice was not taken into account, she may be perceived as aggressive or 'over-sensitive' simply because the male participants are not aware of this issue.

Analysis of powerful men's and women's contributions to meetings from naturalistic data (such as transcripts from the US Senate) indicates there are distinct patterns in how often people contribute and for how long. Powerful men talk more in meetings, but equally-powerful women do not. Unfortunately, this may be because powerful women encounter backlash as a result of talking more than others - they are more likely to be perceived by both men and women as being less likeable, less efficient or too controlling (Brescoll, 2012). According to social norms, men leaders should display their power, but women leaders should not. This is yet another example of the "double bind" faced by women leaders, where they face the choice between being likeable and being competent (see The double bind).

A related issue is the style of the meeting, and the sorts of contribution which are routinely accepted. Academics often enjoy a nice robust debate. It can be a matter of pride to thrash issues out with a lively argument. Supervision meetings can degenerate into point-scoring matches between the supervisors with the student forced into the role of observer; exam boards can degenerate to the point where literally the loudest voice carries the decision; and supposedly consultative staff meetings can be entirely dominated by the most powerful. The drawback of this way of conducting business is that it disenfranchises those whose voices are quieter and roles are less powerful but who nevertheless have extremely useful contributions to make.

This recipe suggests some approaches which can overcome these problems and foster an environment where everyone feels safe to contribute in the knowledge that their views will be heard.

\section{Ingredients}

- A meeting with attendees of varying status, or a single member of a particular demographic group. 


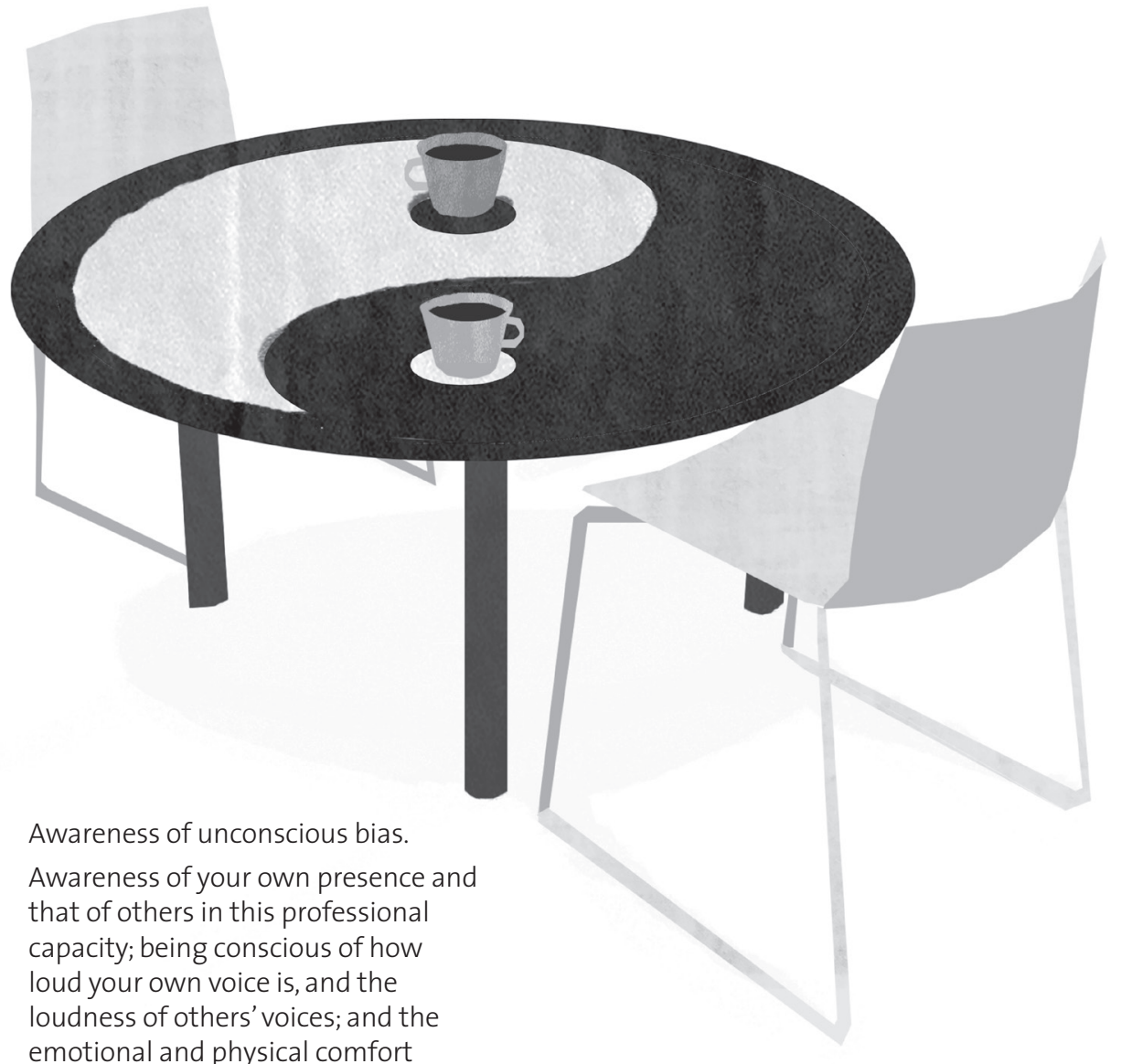

levels of the people around you.

- Preparation time.

- Patience and calm.

\section{Method}

1. Have the meeting at a time which does not exclude people (inside core working hours). Choose a time which does not clash with school drop-off and pick-up times. Try to rotate the days and times of regular meetings so that people who work part-time do not consistently experience scheduling conflicts.

\section{Pick the meeting chair carefully. To} make an inclusive meeting work, you need a resilient, firm chair who is willing to challenge irritating people even if they are senior to them, or higher in an unacknowledged power hierarchy.

3. What to think about if you're the chair. If you have been put in the role of the chair, you can acquire the skills you need with practice and deliberate planning before the meeting. It might also be helpful to have an ally who knows your goals in advance and can help you out in sticky patches. Often you will have to be far firmer and less polite than you would be comfortable with in normal conversation. Perhaps you might need to get over your worries about interrupting people who are older than you or higher up the pecking order. Don't worry about coming across as 'bossy' - this relates to women being perceived as strident or aggressive even when the content of their speech would not be considered in this way if a man said it. 
In the end, it doesn't matter whether you are bossy or not. Your job when running a meeting is to cover the necessary ground, while ensuring that everyone who wishes to contribute can do so, and to get it all done before the end of the allocated time slot. If you have to seem bossy to achieve this, so be it. If you have a naturally quiet voice, you could tap a glass with a spoon (or bang your head off the desk!) to attract attention. If you think the meeting will be pressed for time, you could use a timer which everyone can see, and regularly draw attention to the time remaining to reduce waffle and get decisions made.

\section{Plan the meeting structure to avoid} lengthy periods of verbal debate. Academic meetings can bring out the worst in otherwise perfectly reasonable people. Academics often love to talk, and like to hold forth in lecture-sized chunks. This results in uneven participation because if a couple of people hog the floor, then other views go unheard. Sometimes it is best to disrupt the normal meeting pattern so as not to encourage them. For example, you could ask for email comments beforehand and summarise them, or use an online voting system live for voting during the meeting.

5. Consider whether you can increase the proportion of women at the meeting (or members of a minority group).
The dynamic of the meeting may change when more than one-third of attendees are women and critical mass is achieved (Bohnet, 2016).

6. Deliberately and systematically consult everyone and ensure equal speaking time. You need to strike a careful balance here between putting shy people on the spot and giving them the opportunity to speak. You might have to adopt different techniques depending on the size of the meeting. In small meetings, you could deliberately go round each person at the table in turn to ask them for their view, thanking each person respectfully for what they contributed regardless of their status. In large meetings, you could ask people to write down their views on a piece of paper (anonymously if you prefer) and pin them to the wall so that everyone may browse the views of their colleagues by reading them.

The advantage of this is that you have a record of the views to take away and think about afterwards. It may be necessary to explain why you are doing this to the senior people or the mouthy people who feel aggrieved that they are not getting a chance to hog the discussion as they normally would. You could do this publicly as you introduce the exercise to make the point that you want to hear from everyone.

267 EqualBITE How to run more equal meetings 


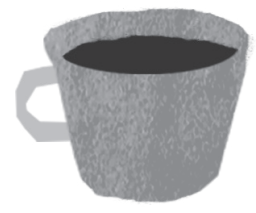

7. Ensure good quality listening in the room. Do this by making sure there is no background noise or individual conversations when anyone is speaking, particularly if someone with a quieter voice is trying to contribute. For a big audience, take the time to set up the microphone right, especially for women.

8. Keep track of who said what. When making the summary of the meeting either orally or in writing, be sure to name equally the persons who suggested the different ideas or contributions. If you're not taking notes yourself, remember to brief the minute-taker at the start of the meeting to specifically include names for each contribution.

- Call out bad behaviour. As the leader of the meeting, it is your job to analyse your own unconscious gender bias (whether you identify as a woman, a man or as in-between or as neither gender) and strive to redirect this act of listening to the whole group as much as you can by intervening and calling it out when you can see it happening. From time to time your colleagues will misbehave by interrupting, dismissing their colleagues' contributions, ignoring or patronising junior people, hogging the floor or 'mansplaining'.

It's your job to civilly draw attention to this as an unacceptable behaviour by way of training the rest of the participants on how to behave and reassuring the recipients of the behaviour that it is OK to speak. Here are some phrases you might find helpful:

- Thank you, Joe, but we have already heard from you and I would like to hear what other people think about this.

- I'll just stopyou there because we need to move on to address $X$.

- $\quad$ [Bill] that's a great issue/ idea to raise, but I believe that [Alice] already raised it earlier. Thank [Alice] after it occurs.

9. Deal fairly with confrontations. If there is a confrontation, be sure that the arguments from a woman or a younger participant are not discarded simply because the other side speaks louder or is more confident.

10. What not to do. Do not make jokes or comments on physical aspects (clothes, hair style, and accessories) or on 'how kind' or 'how nice' women are. Do not assume that all women in the room are on the same side and share the same opinions just because they are women.

11. Good luck. It takes a while to change unconscious bias (it is unconscious after all), but the first step is to acknowledge that it's happening so that other people become aware of it and realise when it's happening and change behaviour accordingly. 